\title{
MicroRNA-155 Promotes Atherosclerosis Inflammation via Targeting SOCS1
}

\author{
Yang Yang ${ }^{\mathrm{a}}$ Lixia Yang ${ }^{\mathrm{b}}$ Xing Liang ${ }^{\mathrm{b}}$ Guofu Zhu ${ }^{\mathrm{b}}$ \\ aDepartment of Postgraduate, Third Military Medical University, Chongqing, China; ${ }^{b}$ Department of \\ Cardiology, Kunming General Hospital of Chengdu Military Area, Yunnan, China
}

\section{Key Words}

MicroRNA-155 • Atherosclerosis • Inflammation • SOCS1

\begin{abstract}
Aims: Accumulating evidence suggests that atherosclerotic progression depends on persistent and chronic inflammation in the arterial walls. MicroRNA-155 is reportedly involved in cardiovascular disease and has been implicated as a pro-inflammation regulator. Although some researchers have focused on microRNA-155 as an atherosclerosis regulator, the mechanisms by which microRNA-155 functions as a putative pro-atherosclerosis microRNA are largely unknown. This study aims to analyze microRNA-155's effects on atherosclerotic inflammation and to explore its mechanism. Methods: MicroRNA-155's effects on atherosclerotic inflammation were observed along with the expression and activity levels of SOCS1, STAT3 and NF-KB though microRNA-155 inhibition or overexpression. Results: Highly expressions of microRNA-155 in oxLDL-stimulated macrophages and atherosclerosis mice were inversely correlated with SOCS1 expression. Ectopic microRNA-155 overexpression significantly promoted inflammatory cytokine and chemokine production and atherosclerosis progression. We then observed microRNA-155's functional role in the atherosclerotic pathophysiological process in vivo and in vitro. The observation revealed that by enhancing STAT3 and NF-KB signaling and facilitating immune inflammation by targeting SOCS1, microRNA-155 plays a promotable role in atherosclerosis progression. Conclusions: microRNA-155 works as a promoter in the atherosclerotic procession. Its mechanism may include enhancing inflammatory response in atherosclerosis by increasing STAT3 and NF-KB signaling via targeting SOCS1.

Copyright (C) 2015 S. Karger AG, Basel
\end{abstract}

\section{Introduction}

Atherosclerosis is one of the leading causes of morbidity and mortality worldwide. Its key cellular elements include hyperlipidemia, monocyte recruitment, differentiation into macrophages, foam cell formation, and induced inflammation [1]. Accumulating evidence

Lixia Yang

KARGER 125
Department of Cardiology, Kunming General Hospital of Chengdu Military Area, Yunnan, 650032, (China)

Tel. +86-18523452531, Fax +86-021-64085875, E-Mail lwyyyang@163.com 
supports that persistent, chronic inflammation plays a critical role in atherosclerotic complex pathological process [2]. Many pro-inflammatory genes are activated by the induced innate immunity signaling pathways in macrophages and produce a broad range of cytokines that exert pro-inflammatory and anti-inflammatory effects at all atherosclerotic stages [3-5]. Therefore, the immune system regulators involved in inflammatory responses are vital in mediating atherosclerosis, like many microRNAs (miRNAs) [1, 6].

miRNAs are 18-22 nucleotides long and are non-coding RNA molecules that regulate gene expression post-transcriptionally by triggering either translation repression or RNA degradation [7]. Recent studies uncovered their profound and unexpected roles in inflammation and immune responses and in controlling the diverse cardiovascular functions [8-10]. Heymans et al. showed that pressure overload triggers the cardiac infiltration of miR-155-expressing monocytes/macrophages, and macrophage miR-155 promotes cardiac hypertrophy and failure in mice [11]. MicroRNA-155(miR-155) is highly expressed in activated macrophages and is up-regulated in oxidized low-density lipoprotein (oxLDL)-stimulated monocytes $[12,13]$. Nazari-Jahantigh et al. reported the increase of miR-155 in ACS patients could promote atherosclerosis by repressing Bcl6 in macrophages [14]. Currently, 26 miR-155 targets have been experimentally validated, including many transcriptional regulatory proteins, kinases, and nuclear and DNA-binding proteins [15]. SOCS1 is a direct anti-inflammatory target of miR-155 [16,17]. It is a tumor suppressor that normally functions as a negative feedback regulator of Janus activated kinase (JAK)/signal transducer and activator of transcription (STAT) signaling [18]. Here, we show that miR155 overexpression in atherosclerosis model mice and in oxLDL stimulated macrophages promoted atherosclerotic progression and inflammatory response by repressing SOCS1. Furthermore, we noted SOCS1 was an efficient miR-155 target in modulating atherosclerosis inflammation by enhancing STAT3 and NF- $\mathrm{\kappa B}$ signaling activation. These collective results suggest that miR-155 acts as a promoter in atherosclerosis by targeting SOCS1.

\section{Materials and Methods}

\section{Cell culture}

The human monocytic cell-line THP-1 were maintained at a $10^{6} / \mathrm{ml}$ density in RPMI 1640 medium supplemented with 10\% fetal bovine plasma (Sigma) and placed them in a 5\% CO2 incubator at $37{ }^{\circ} \mathrm{C}$. 100nM PMA were used to induce monocyte differentiation to macrophages [19], and then stimulated with oxLDL $(50 \mu \mathrm{g} / \mathrm{ml})$. MiR-155 mimics and inhibitor (GenePharma Co., Ltd.) were transfected at a final concentration of $150 \mathrm{nM}$ using lipofectamine 2000 (Invitrogen). We collected the cell culture supernatant for ELISA analysis and extracted total RNA and protein for real-time PCR and western blot.

\section{Cloning 3'UTR of SOCS1 $\mathrm{mRNA}$ and reporter gene assay}

The wild type SOCS1-3'UTR and mut-SOCS1-3'UTR dual luciferase reporter vector (Promega) were synthetized and tested by GenePharma Co., Ltd. and were then co-transfected with miR-155 mimic or inhibitor in oxLDL-stimulated macrophages. Cells were also transfected with the pmirGLO-control vector, which is useful for monitoring transfection efficiency. We used miR-155 negative control, a miRNA nonhomologous to the human genome, as a control. After $24 \mathrm{~h}$, we determined firefly luciferase activity using the dual luciferase reporter assay system (Promega) under a GloMAX 20/20 Luminometer (Promega). We obtained relative reporter activity through normalization to the Renilla control.

\section{Small RNA transfection}

We synthesized RNA oligonucleotides for small interference RNA (siRNA) (GenePharma) with the following: for negative control, 5' - UUC UCC GAA CGU GUC ACG UTT-3' (sense), 5' - ACG UGA CAC GU UCG GAG AAT T-3' (anti-sense); for SOCS1, 5' - GAA CCU UCC UCC UCU UCC UCC UCC T-3' (sense), 5' - AGG AGG AGG AAG AGG AGG AAG GUU CUG-3' (anti-sense). PMA-induced THP-1 macrophages were transfected with $100 \mathrm{nM}$ siRNA for $24 \mathrm{~h}$, followed by oxLDL (50ug/ml) for another $24 \mathrm{~h}$.

\section{KARGER}




\section{Cellular Physiology Cell Physiol Biochem 2015;36:1371-1381 \begin{tabular}{l|l} 
and Biochemistry Published onlIne: July UI, 2015 & $\begin{array}{l}\text { C) 2015 S. Karger AG, Basel } \\
\text { www.karger.com/cpb }\end{array}$ \\
\hline
\end{tabular}}

Yang et al: SOCS1-miR-155 and Atherosclerosis Inflammation

Quantitative RT-PCR

We performed quantitative RT-PCR analyses for miRNAs using TaqMan miRNA assays (Ambion) in a Rotorgene 6000 Thermocycler (Corbett Life Science), using the following parameters: $95^{\circ} \mathrm{C}$ for $20 \mathrm{~s}$, followed by 40 cycles of $95^{\circ} \mathrm{C}$ for $15 \mathrm{~s}, 60^{\circ} \mathrm{C}$ for $30 \mathrm{~s}$, and $70^{\circ} \mathrm{C} 10 \mathrm{~s}$. We used U6 small nuclear RNA as an endogenous control for data normalization and calculated the relative expression using the comparative threshold cycle method.

hsa-miR-155 mimics: (5'to 3') F: UUAAUGCUAAUCGUGAUAGGGGU

(5'to 3') R: ACCCCUAUCACGAUUAGCAUUAA

hsa-miR-155 inhibitor: ACCCCUAUCACGAUUAGCAUUAA

negative control for each one:

mimics control: (5'to 3') F: UCACAACCUCCUAGAAAGAGUAGA

(5'to 3') R: UCUACUCUUUCUAGGAGGUUGUGA

Inhibitor control: (5'to 3') F: UCUACUCUUUCUAGGAGGUUGUGA

We performed quantitative RT-PCR analyses for the mRNA using PrimeScript RT-PCR kits (Takara) and used the mRNA level of $\beta$-actin as an internal control. The real-time PCR program steps included: $95^{\circ} \mathrm{C}$ for $1 \mathrm{~min}, 40$ cycles of $95^{\circ} \mathrm{C}$ for $5 \mathrm{~s}, 60^{\circ} \mathrm{C}$ for $5 \mathrm{~s}$, and $72^{\circ} \mathrm{C}$ for $20 \mathrm{~s}$. The primer sequences are shown as follows: SOCS1, $5^{\prime}$ - CTT CTG TAG GAT GGT AGC ACA C - $3^{\prime}$ (sense), $5^{\prime}$ - AGG AAG AGG AGG AAG GTT CT - $3^{\prime}$ (anti-sense); TNF- $\alpha, 5^{\prime}$ - GAT CCC TGA CAT CTG GAA TCT G - $3^{\prime}$ (sense), 5'- GAA ACA TCT GGA GAG AGG AAG G - $3^{\prime}$ (antisense); IL-1 $\beta, 5^{\prime}-$ CTC TCA CCT CTC CTA CTC ACT T-3' (sense); 5'- TCA GAA TGT GGG AGC GAA TG - $3^{\prime}$ (anti-sense); CCL2 , 5' - GCA GAA GTG GGT TCA GGA TT - $3^{\prime}$ (sense); 5' - ATT CTT GGG TTG TGG AGT GAG - $3^{\prime}$ (anti-sense); CCL4, $5^{\prime}$ - GTA CGT GTA TGA CCT GGA ACT G - $3^{\prime}$ (sense), $5^{\prime}$ - AGT CCT GAG TAT GGA GGA GAT G -3' (anti-sense); CCL7, 5' - GGC TGA GAC CAA ACC AGA AA - $3^{\prime}$ (sense), 5' - GTG AGC AGC AGA CAC AGA A - $3^{\prime}$ (anti-sense); $\beta$-actin, $5^{\prime}$ - GGA TCA GCA AGC AGG AGT ATG - $3^{\prime}$ (sense), $5^{\prime}$ - AGA AAG GGT GTA ACG CAA CTA A -3' (anti-sense).

\section{Western blot analysis}

Protein extracts were denatured and the solubilized proteins $(40 \mu \mathrm{g})$ subjected to electrophoresis on $10 \%$ polyacryl amide SDS gels. We then probed with antibodies for SOCS1, STAT3, phospho-STAT3 (Abcam), I $\kappa B \alpha$, phosphor-I $\kappa B \alpha$, and $\beta$-actin (Santa Cruz) (diluted 1:500, $\beta$-actin diluted 1:2000 in TBST), and then we used goat anti-rabbit secondary antibody labeled with far-red-fluorescent Alexa Fluor 680 dye. We detected the immunofluorescence signal using a SuperSignal West Femto Maximum Sensitivity Substrate kit (ThermoPierce) and performed densitometric analysis using Image Lab (Bio-Rad).

\section{ELISA assays}

We analyzed cell or serum supernatants to determine the presence of TNF- $\alpha$, IL-1 $\beta$, CCL2, CCL4 and CCL7 using Enzyme Immunoassay kits (eBioscience or Uscn Life Science, Inc.) according to the manufacturer's instructions. The values were determined in more than three independent experiments and are represented as the means \pm SD. We extracted nuclear proteins to assay NF- $\kappa B$ in each sample's nucleic protein using the Trans-AM NF- $\kappa$ B p50 Transcription Factor Assay Kit (Active Motif) according to the manufacturer's instructions.

\section{In vivo assay}

We purchased C57BL/6J mice from the Experimental Animal Center of the Third Military Medical University (Chongqing, China) and ApoE-/- mice from the BeiJing Xie He Medicine College (BeiJing, China). The 6-week-old male ApoE-/- mice $(n=16)$ were fed a high-cholesterol diet (1.25\% of cholesterol) for 12 weeks to build an atherosclerosis mouse model, and 6-week-old male C57BL/6 mice (n=8) were fed a normal diet as a control. ApoE gene knockout mice showed symptoms of high blood lipid abnormalities and were then divided into two groups $(n=8)$ : the first group was injected with mismatched miR-155 and the second with antagomiR-155(chemically modified antisense oligonucleotides). Mismatched miR-155 and antagomiR-155 were synthesized by GenePharma Co., Ltd. We began treatment 12 weeks after feeding mice a high-cholesterol diet, and they then received $0.2 \mathrm{ml}$ saline and antagomir-155 via tail vein injections. They received three injections in three consecutive days at $80 \mathrm{mg} / \mathrm{kg}$ body weight $[20,21]$. All animal studies were approved by the Animal Care and Ethics Committee of the Third Military Medical University. 
Analysis of atherosclerotic plaque size and composition

Three weeks after antagomir-155 treatment, we anesthetized mice with an intraperitoneal chloral hydrate injection $(5 \%, 4 \mu \mathrm{l} / \mathrm{g})$, took blood from the apical, and then separated and collected the thoracicabdominal aorta (spanning from the aortic arch to the iliac artery branch) after saline infusion. We performed morphometric and immunohistochemical studies in the thoracic-abdominal aorta and assessed lesion size and composition as previously described [22] .We took serial sections throughout the entire aortic valve area and routinely stained them with hematoxylin and eosin. To quantitate plaque size, we acquired the images of 3 sections with a DP70 digital camera connected to a microscope (Olympus) and determined lesion areas using Image-Pro plus v 6.0 software (Media Cybernetics, Inc.). We used the mean value of plaque cross-sectional areas from 3 sections to estimate the extent of atherosclerosis for each animal. We performed immunohistochemical analyses using the following primary antibodies: anti-mouse CD68 (Santa Cruz), anti-SOCS1 (Santa Cruz), and anti-SMA (Abcam). We analyzed at least 4 sections per animal for each immuno-staining.

Statistical analysis

We performed all statistical analyses using SPSS 19.0 software. Results are shown as the means \pm SD. We determined statistical differences by Student's t-tests or one-way ANOVA. P-values $<0.05$ were considered statistically significant.

\section{Results}

SOCS1 is a target of miR-155 in oxLDL-stimulated macrophages

To understand the biological role underlying the SOCS1-miR-155 interaction in atherosclerosis, we cloned the wild type and mutant SOCS1-3'UTR gene containing the miR155 recognition site by inserting it downstream to a luciferase reporter. We then performed the dual luciferase assay in oxLDL-stimulated macrophages cotransfected with miR-155 mimic/inhibitor. Compared with the wild type SOCS1-UTR plasmid transfection, the relative luciferase activity was statistically significantly decreased or increased following cotransfection with miR-155 mimic or inhibitor(Fig. 1B, P<0.01). Conversely, we observed no luciferase change in cells cotransfected with mutant SOCS1-UTR constructs (Fig. 1B, P>0.05). For better detection, we transfected miR-155 mimic and inhibitor into oxLDL-induced macrophages. Results showed that miR-155 mimic led to a significant decrease, while miR155 inhibitor led to an obvious increase of SOCS1 mRNA and protein levels, relative to the miR-155 control group transfected with a negative control miRNA(Fig.1C-D, $\mathrm{P}<0.01$ ).

Inverse correlation of miR-155 and SOCS1 in oxLDL-stimulated macrophages and in atherosclerosis model mice

To understand the biological role underlying the SOCS1-miR-155 interaction in atherosclerosis, we initially examined SOCS1 and miR-155 expression levels in oxLDLstimulated macrophages and in atherosclerosis model mice. Real-time PCR results showed significantly up-regulated miR-155 levels from oxLDL-stimulated macrophages from 24 to $72 \mathrm{~h}$ (Fig. 2A, ${ }^{\#} \mathrm{P}<0.01$ ). Conversely, mRNA and protein levels of SOCS1 were gradually decreased from 24 to $72 \mathrm{~h}$ after oxLDL stimulation (Fig. $2 \mathrm{~B}-\mathrm{C}$, ${ }^{\#} \mathrm{P}<0.01$ ). Furthermore, we examined SOCS1 and miR-155 expressions in 16 thoracic-abdominal aorta samples (vessel tissue) from atherosclerosis mice and paired C57BL/6 mice. As expected, miR-155 levels were commonly and significantly elevated in atherosclerosis mice samples, and SOCS1 mRNA was obviously reduced in atherosclerosis mice compared to C57BL/6 mice (Fig. 2D). Using Pearson's correlation analysis of SOCS1-miR-155 expression, we obtained a statistically significant inverse correlation ( $\mathrm{R}=-0.892, \mathrm{P}=0.000)$ (Fig. 2D).

These collective results indicate that miR-155 expression is inversely correlated with SOCS1 expression in oxLDL-stimulated macrophages and in atherosclerosis mice, suggesting that SOCS1-miR-155 interactions may have biological significance in atherosclerosis. 


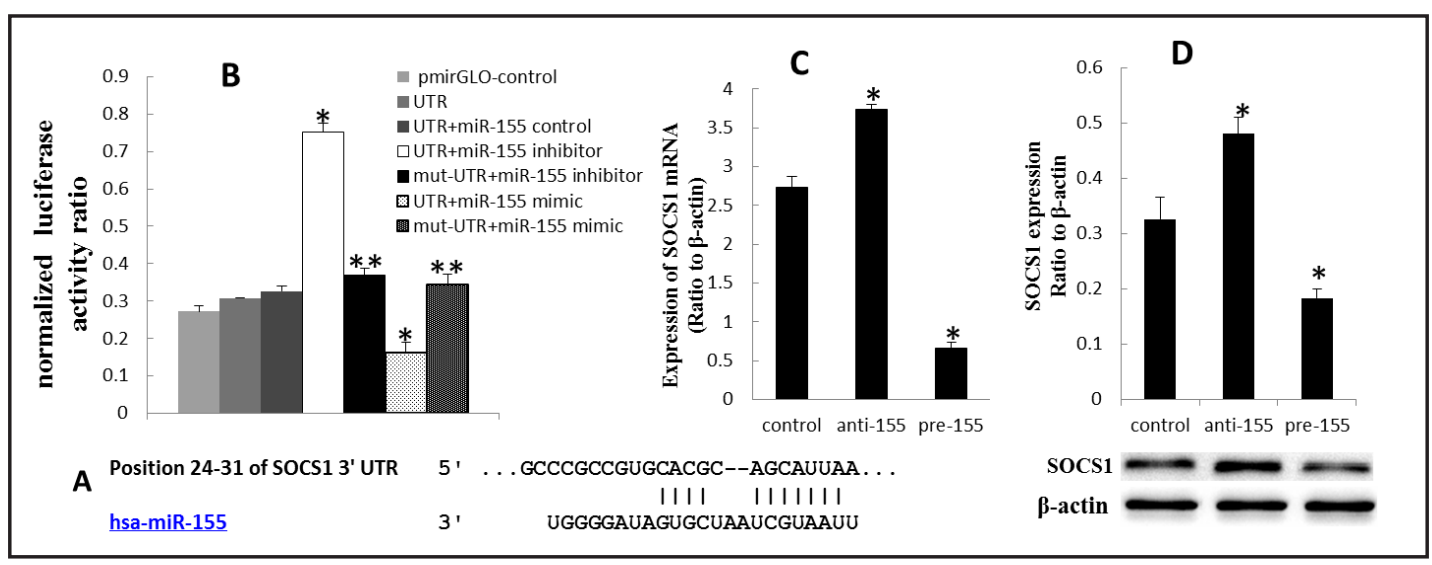

Fig. 1. SOCS1 is a target of miR-155 in oxLDL-induced macrophages. (A) The region of the human SOCS1 mRNA 3'UTR predicted to be targeted by miR-155 (TargetScan 6.2). (B) PMA-induced THP-1cells were stimulated by oxLDL $(50 \mu \mathrm{g} / \mathrm{ml})$ for $24 \mathrm{~h}$, then cotransfected with p-SOCS1-UTR, p-mut-SOCS1-UTR, pmirGLO control, miR-155 control, and miR-155 inhibitor/mimic. Luciferase values were normalized by the Renilla control's luciferase activity. Each construct's luciferase activity ratio was calculated by a luminometer( $\mathrm{n}=3$ ), ${ }^{*} \mathrm{P}<0.01,{ }^{* *} \mathrm{P}>0.05$, compared with the pmirGLO-SOCS1-3'UTR plasmids only group (pmirGLO-control). (C) and (D) Effects of miR-155 mimic(pre-155) and inhibitor (anti-155) on SOCS1mRNA and protein levels in oxLDL-stimulated macrophages, analyzed by real-time PCR and western blot, respectively. Band densities were measured by Image Lab software(n=3), ${ }^{\mathrm{P}}<0.01$ compared with the miR-155 negative control group (control).

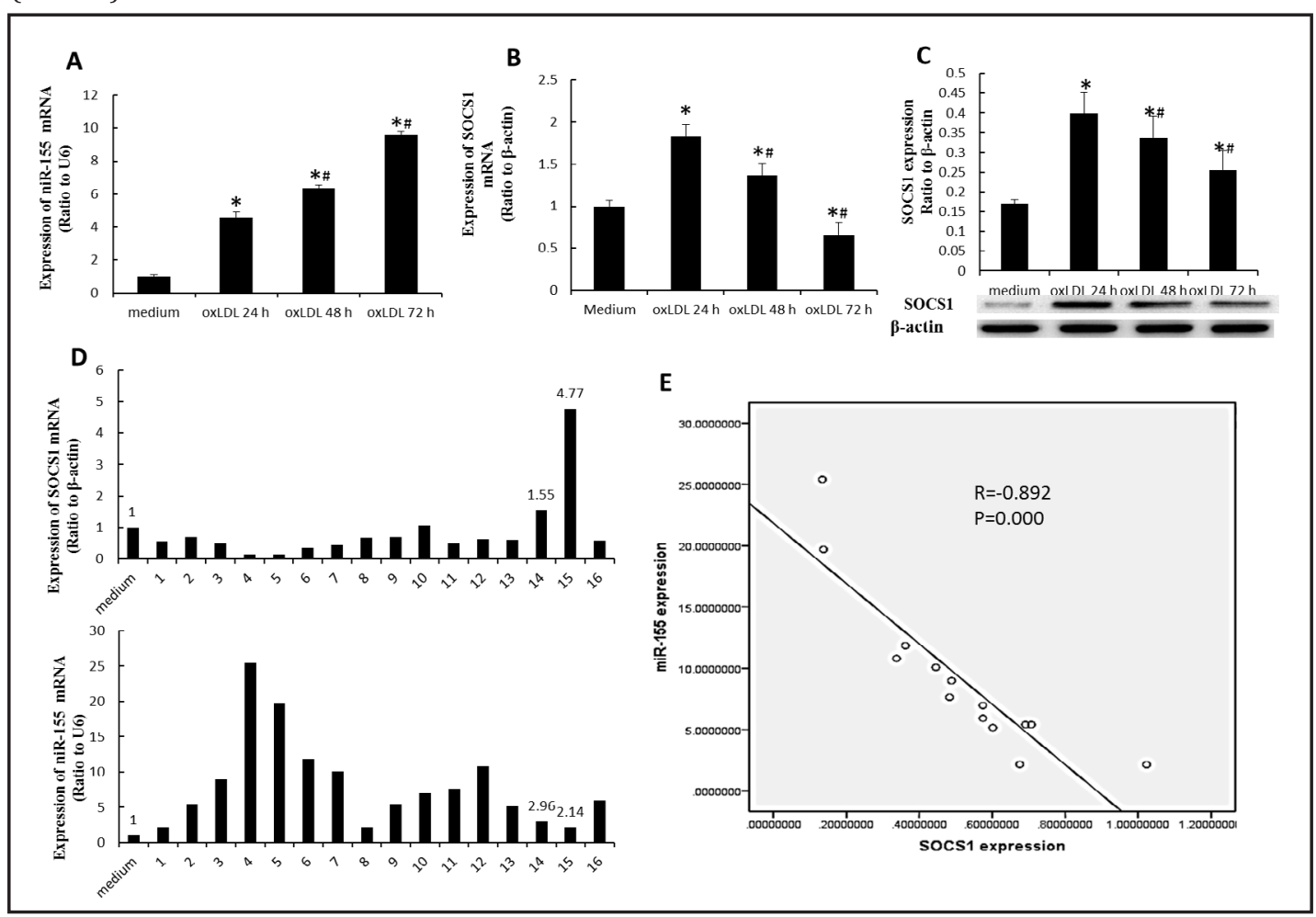

Fig. 2. Relative expression levels of miR-155and SOCS1 in oxLDL-stimulated macrophages and atherosclerotic mice. PMA-induced THP-1 macrophages were stimulated with oxLDL(50 $\mu \mathrm{g} / \mathrm{ml}$ ) for $72 \mathrm{~h},(\mathrm{~A})$ and (B) miR-155 and SOCS1 mRNA levels were analyzed by real-time PCR(n=3), (C) protein levels of SOCS1 were determined by $\mathrm{WB}(\mathrm{n}=3)$, ${ }^{*} \mathrm{P}<0.01$ compared with medium, ${ }^{*} \mathrm{P}<0.05$ compared with oxLDL $24 \mathrm{~h}$. (D) Vessel tissues of atherosclerosis mice and C57BL/ 6 mice were collected for detection of miR-155 and SOCS1 mRNA levels $(n=16)$. (E) This graph indicated a statistically significant inverse correlation $(R=-0.892, P=0.000)$ in 14 of 16 samples.

\section{KARGER}




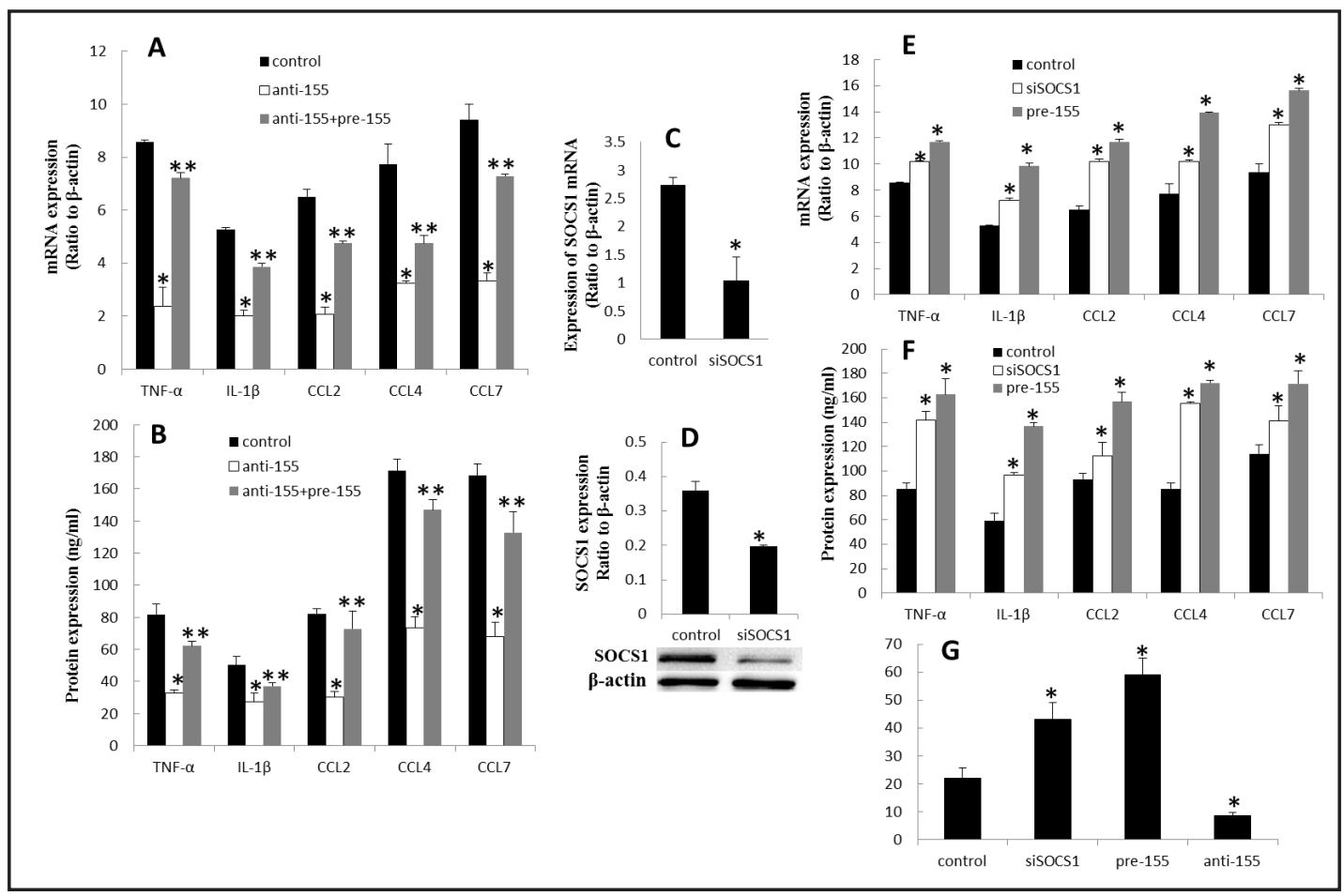

Fig. 3. miR-155 enhanced inflammatory cytokine and chemokine secretion and macrophage migration in

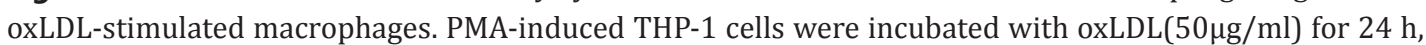
followed by miRNA mimic/inhibitor were transfection for another $24 \mathrm{~h}$. TNF- $\alpha$, IL-1 $\beta$, CCL2, CCL4, and CCL7 expression levels were regulated after miR-155 inhibitor and mimic incubation. (A) and (B) The mRNA and protein levels of TNF- $\alpha$, IL-1 $\beta$, CCL2, CCL4, and CCL7 were analyzed by real-time PCR and ELISA. Small interference RNAs for SOCS1 (siSOCS1) or a negative control sequence were transfected in oxLDL-stimulated macrophages.(C) and (D) SOCS1 mRNA and protein levels were detected by real-time PCR and western blot. (E) and (F) Detection of mRNA and protein levels of TNF- $\alpha$, IL-1 $\beta$, CCL2, CCL4, and CCL7. (G) Transwell analysis of macrophage migration. All data (means $\pm \mathrm{SD}$ ) were from three independent experiments. ${ }^{*} \mathrm{P}<0.01$ versus the miR-155 control or siRNA control group (control), ${ }^{* *} \mathrm{P}<0.01$ versus the miR-155 inhibitor group (anti-155) group.

miR-155 promoted inflammation and macrophage migration in oxLDL-stimulated macrophages

To further study miR-155's role in the atherosclerosis inflammatory response, we used miR-155 inhibitor and mimic in oxLDL stimulated macrophages. Results showed that secretions of inflammatory cytokines TNF- $\alpha$ and IL-1 $\beta$, as well as chemokines CCL2, CCL4 and CCL7, were decreased after miR-155 inhibitor treatment, and this decrease could be counteracted by miR-155 mimic (Fig.3A-B, ${ }^{*} \mathrm{P}<0.01$ ). For better detection, we used siRNAs to knockdown SOCS1 in oxLDL-stimulated macrophages. The SOCS1 expression knockdown via siRNA treatment efficiently repressed SOCS1 mRNA and protein levels (Fig. $\left.3 \mathrm{C}-\mathrm{D},{ }^{*} \mathrm{P}<0.01\right)$. As expected, SOCS1 knockdown led to increased TNF- $\alpha$, IL-1 $\beta$, CCL2, CCL4 and CCL7, at both the mRNA and protein levels. These observations were similar to those results following miR-155 mimic treatment (Fig.3E-F, ${ }^{*} \mathrm{P}<0.01$ ). The results of transwell showed that miR-155 overexpression or SOCS1 knockdown with its specific siRNA led to increased macrophage migration, whereas when miR-155 was downregulated by inhibitor, the migrated macrophages decreased statistically (Fig. $3 \mathrm{G},{ }^{*} \mathrm{P}<0.01$ ).

miR-155 enhanced STAT3 and NF- $\kappa B$ signaling in oxLDL-stimulated macrophages

SOCS1 is a tumor suppressor that normally functions as a negative feedback regulator of JAK/STAT signaling[18]. Recent evidence indicates that STAT3 collaborates with NF-кB 


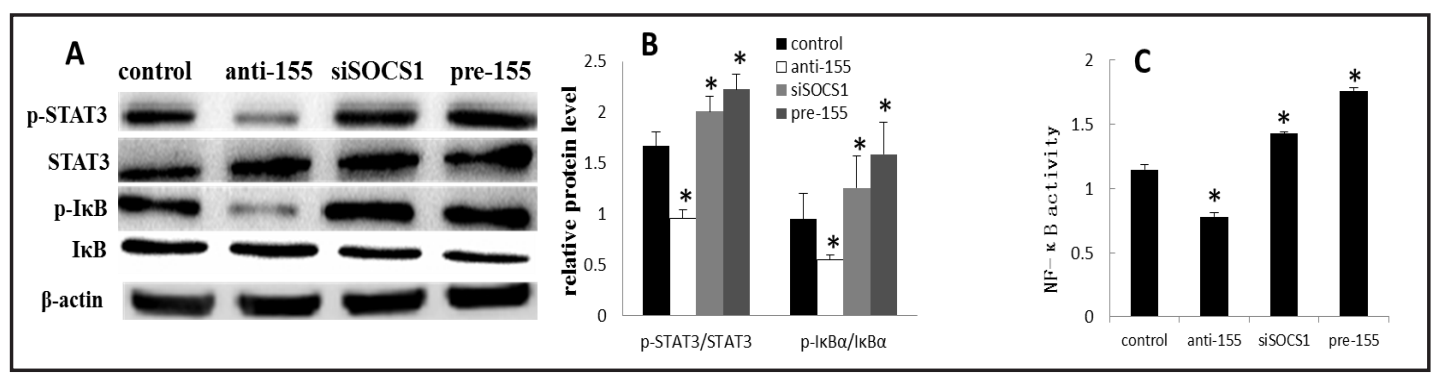

Fig. 4. miR-155 enhanced the STAT3 and NF- $\kappa B$ signaling in oxLDL-stimulated macrophages. (A) The phosphorylation and total protein levels of STAT3 and IкB $\alpha$ analyzed by western blot. (B) Band densities were measured by Image Lab software. (C) NF- $\mathrm{BB}$ transcript activation of oxLDL-stimulated macrophages detected by ELISA. All data (means $\pm \mathrm{SD}$ ) were from three independent experiments. ${ }^{*} \mathrm{P}<0.05$ versus the miR-155 control group.

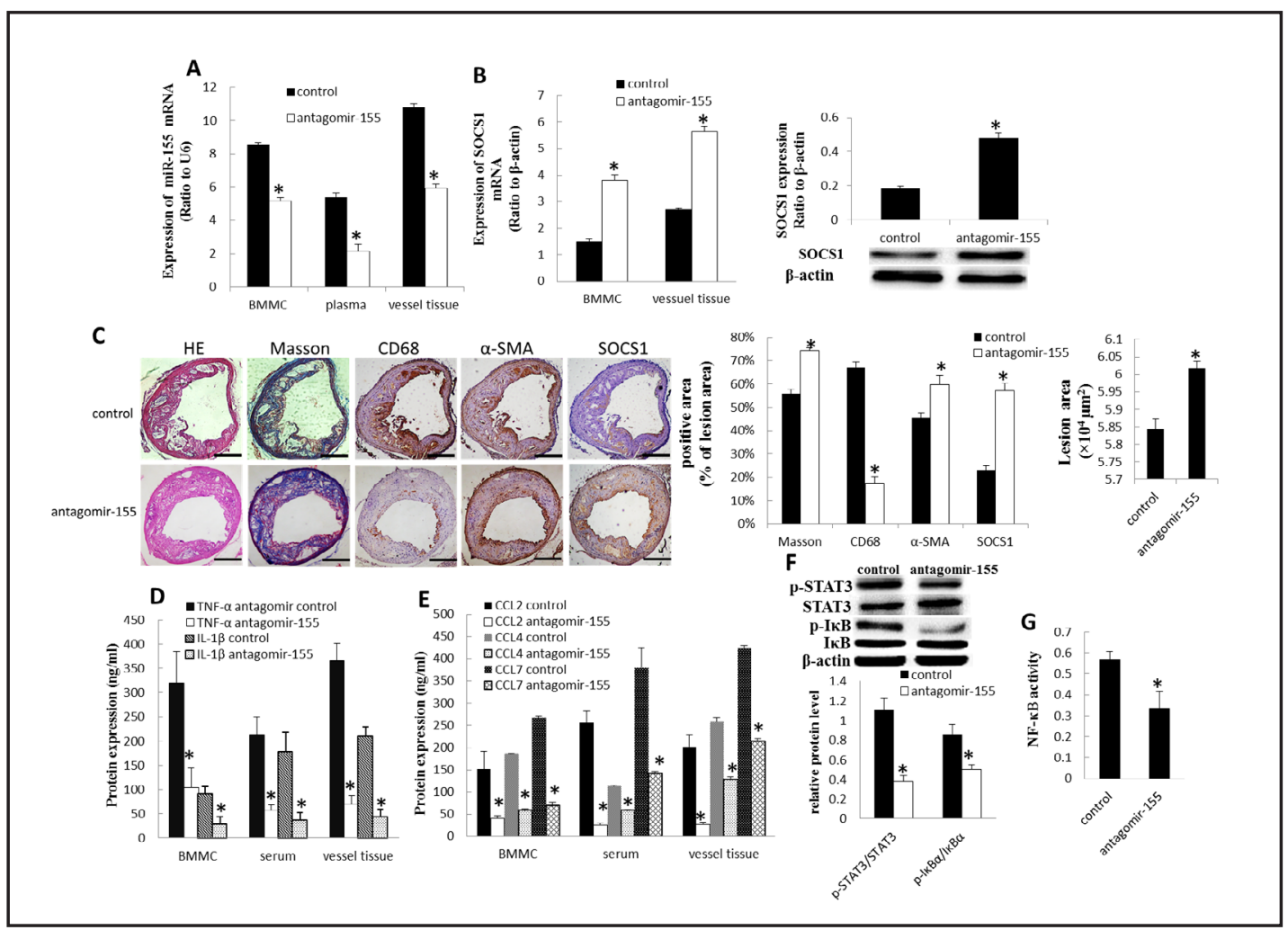

Fig. 5. Antagomir-155 attenuated atherosclerosis development and progression in an atherosclerosis mouse model. (A)Detection of miR-155 expression level in atherosclerosis models after treatment with antagomir-155 or antagomir negative control (control) by real-time PCR. *P $<0.01$ relative to control. (B) Analysis of SOCS1 mRNA and protein levels in the antagomir-155 group by real-time PCR and western blot. Band densities were measured by Image Lab software. ${ }^{*} \mathrm{P}<0.01$ relative to control. (C)Paraffin-embedded cross sections from antagomir negative control or antagomiR-155-infused ApoE ${ }^{-/}$mice were obtained throughout the thoracic-abdominal aorta area and stained with HE, Masson, CD68 antibody, $\alpha$-SMA antibody, and SOCS1 antibody, as well as rat or rabbit nonspecific IgG, respectively. Images were quantified with Image-Pro Plus 6.0 at a $100 \times$ or $200 \times$ magnification. The scale is $100 \mu \mathrm{m}$. Data are represented as means \pm SD $(n=8) . * P<0.05$ relative to control.(D) and (E) ELISA analysis of TNF- $\alpha$, IL-1 $\beta$, CCL2, CCL4, and CCL7 secretion in serum, vascular tissues, and BMMCs. (F) The phosphorylation and total protein levels of STAT3

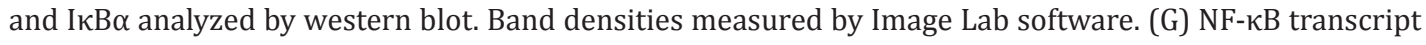
activation detected by ELISA. All data (means \pm SD) were from three independent experiments. ${ }^{*} \mathrm{P}<0.05$ versus the antagomir-155 negative control group.

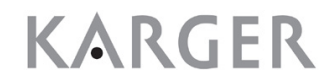


to regulate certain gene expressions [23]. Therefore, we were interested in determining the involvement of STAT3 and NF- $\kappa$ B signaling in miR-155's inflammatory effect. We transfected oxLDL-stimulated macrophages with miR-155 inhibitor, miR-155 mimic, and siSOCS1. Western blot results showed that miR-155 inhibitor significantly downregulated STAT3 and I $\kappa \mathrm{B} \alpha$ phosphorylation, but siSOCS1 and miR-155 mimic increased the phosphorylation (Fig. 4A-B). Furthermore, miR-155 inhibitor could downregulate, iSOCS1 and miR-155 mimic could upregulate NF- $\mathrm{KB}$ activity in oxLDL in macrophages (Fig. 4C).

Inhibition of miR-155 attenuated atherosclerosis development and inflammation in an atherosclerosis mouse model

To test whether miR-155 inhibition was beneficial for atherosclerosis, we blocked miR155 via tail-vein antagomir-155 injection in ApoE $/$ mice with a high-fat diet. Real-time PCR analysis showed that antagomir-155 significantly inhibited miR-155 levels in the mice's plasma, vessel tissues (thoracic-abdominal aortas) and BMMCs (Fig.5A, $\mathrm{P}<0.05$ ). Meanwhile, we detected an obvious SOCS1 increase in both mRNA and protein levels in the antagomir-155 group (Fig.5B, $\mathrm{P}<0.05$ ). We separated the mice's thoracic-abdominal aortas to observe the atherosclerotic lesions and analyzed the results using IPP 6.0 software. Consistent with the above results, the SOCS1-positive area was increased after antagomir-155 treatment (Fig.5C, $\mathrm{P}<0.05)$. Although the lesion areas did not decrease after antagomiR-155 treatment, we observed a decrease in the positive area for atherosclerosis plaque macrophages (CD68), an increase in collagen deposition and the SMA-positive area in the antagomiR-155-treated group compared to the antagomir negative control(Fig. $5 \mathrm{C}, \mathrm{P}<0.01$ ).

Additionally, TNF- $\alpha$, IL-1 $\beta$, CCL2, CCL4, and CCL7 secretions in serum, vascular tissues and BMMCs were significantly downregulated by antagomir-155 compared to the antagomir negative control(Fig. 6D-E, $\mathrm{P}<0.01$ ). STAT3 and NF- $\kappa \mathrm{B}$ signaling were inhibited after antagomir-155 treatment (Fig. $6 \mathrm{~F}-\mathrm{G}, \mathrm{P}<0.01$ ). These data show that inhibiting miR155 reduces macrophage accumulation and alleviates inflammation in atherosclerosis, suppresses atherosclerotic plaque development.

\section{Discussion}

Accumulating evidence suggests that inflammation drives the formation, progression, and rupture of atherosclerotic plaques [23]. Therefore, focusing on the potential targets of inflammatory processes in atherosclerosis would provide novel treatment strategies [2].

Many miRNAs play an important role in atherogenesis [10, 24-26]. For example, miR-126 is reportedly an anti-atherosclerosis microRNA since it regulates angiogenesis and vascular inflammation [27] and miR-150 promotes atherosclerosis via enhancing the targeted endothelial cell migration [28]. miR-155 may be one miRNA which plays an important role in atherosclerosis. It reportedly increases in ACS patients and could promote atherosclerosis by repressing Bcl6 in macrophages [14]. Wei Y et al. reported that the microRNA-342-5p could foster inflammatory macrophage activation through an Akt1- and microRNA-155-dependent pathway during atherosclerosis [17]. Qing Jing et al. found that elevated microRNA-155 promotes foam cell formation by targeting HBP1 in atherogenesis [29]. Among miR-155's targets, SOCS1 attracted our attention. SOCS1 is a powerful attenuator of JAK/STAT signaling [30] and has more recently been shown to disrupt NF- $\kappa B$ and the JNK and p38 pathways [23, 31]. Activation of NF- $\kappa B$ is reported to be higher in patients with ACS and in oxLDL-induced mast cells $[32,33]$. Also, STAT3 signal pathway is reported to be involved in atherosclerosis inflammation [34]. Thus, we wished to investigate the role of SOCS1-miR-155 in regulating the atherosclerotic vascular inflammation response to find new therapeutic strategies for treating atherosclerosis and other vascular diseases.

First, we confirmed SOCS1 as a target of miR-155 in oxLDL-induced macrophages. We then observed miR-155 and SOCS1 levels in oxLDL-stimulated macrophages and in atherosclerosis model mice. We noticed a statistically significant inverse correlation between 
SOCS1 and miR-155expressions, suggesting a significant biological function of SOCS1-miR155 in atherosclerosis. Since miR-155 mimic led to a significant decrease, while miR-155 inhibitor led to an obvious increase of SOCS1 mRNA and protein expressions, we proposed that high miR-155 levels are likely responsible for low SOCS1expression levels in oxLDLstimulated macrophages.

Considering miR-155 is involved in some aspects of the atherosclerotic pathological process and inflammation [29, 35, 36], we hypothesized that SOCS1-miR-155 was deeply involved in regulating atherosclerosis inflammation. The present results showed that ectopic high levels of miR-155 as well as siSOCS1 could increase, and blocking miR-155 could decrease the production and secretion of some pro-inflammatory cytokines and chemokine in oxLDL-stimulated macrophages, which could lead to increased monocyte recruitment to plaque and promote atherosclerosis progression. These results confirmed our hypothesis that miR-155 acts as a promoter of inflammation in oxLDL-stimulated macrophages partly via targeting SOCS1. miR-155 greatly influenced the production and secretion of inflammatory cytokines and chemokines,

SOCS1 functions most classically to limit IFN activation of STATs(namely STAT1, STAT2, and STAT3) $[37,38]$. Ryo A et al. gave evidence indicating that STAT3 collaborates with NF- $\mathrm{B}$ to regulate certain gene expressions [23], and Guo J et al. reported IKBKE as a direct target of STAT3[39], which could activate NF- $\mathrm{KB}$ and STAT signaling [39, 40]. Our results also showed that miR-155 could enhance STAT3 and NF- $\kappa$ B signaling in oxLDL-stimulated macrophages. Furthermore, we noticed that siSOCS1 was less efficient than miR-155 mimic at inducing atherosclerosis inflammation, suggesting that other targets might be involved in miR-155's promotable function in oxLDL-stimulated macrophages. Upon using antagomir-155 to block miR-155 expression in ApoE $/$ mice with high fat diets, the positive area for atherosclerosis plaque macrophages decreased, the collagen deposition and the SMA-positive area increased, suggesting that the plague may be stable, although the lesion area was increased slightly, the continuous high-fat diet could be one of the important reasons. Besides, we noticed that inhibiting miR-155 alleviated inflammation, as well as STAT3 and NF- $\kappa$ B signaling in vivo.

The present study's collective results suggested miR-155's pro-atherosclerotic effect occurs by promoting atherosclerosis inflammation partially via targeting SOCS1 to enhance STAT3 and NF- $\kappa B$ signaling. Considering antagomir-155 has clinically acceptable virtues like easy dose control, drug-like properties, and high effectiveness in over-expressing target miRNA with long-lasting efficacy under in vivo conditions $[41,42]$, it may offer some new insights regarding atherosclerosis treatment [43].

\section{Acknowledgments}

We would like to thank all members of the Cardiology Department of Kunming General Hospital and the Medical Research Center of the Southwest Hospital of the Third Military Medical University for assistance, we thank Professor Jiang Zheng for equipment support.

\section{Disclosure Statement}

The authors have not disclosed any potential conflicts of interest.

\section{References}

\footnotetext{
1 Hansson GK: Inflammation, atherosclerosis, and coronary artery disease. N Engl J Med 2005;352:16851695.

- Imanishi T, Akasaka T: Novel strategies to target inflammatory processes in atherosclerosis. Curr Pharm Design 2013;19:1616-1625.
} 


\section{Cellular Physiology Cell Physiol Biochem 2015;36:1371-1381 \begin{tabular}{l|l} 
and Biochemistry Published onlIne: July UI, 2015 & $\begin{array}{l}\text { C) 2015 S. Karger AG, Basel } \\
\text { www.karger.com/cpb }\end{array}$ \\
\hline
\end{tabular}}

Yang et al: SOCS1-miR-155 and Atherosclerosis Inflammation

3 Gui T, Shimokado A, Sun Y, Akasaka T, Muragaki Y: Diverse roles of macrophages in atherosclerosis: from inflammatory biology to biomarker discovery. Mediators Inflamm 2012;693083.

4 Libby P: Inflammation in atherosclerosis. Arterioscler Thromb Vasc Biol 2012; 32: 2045-2051.

5 Wang H, Eitzman DT: Acute myocardial infarction leads to acceleration of atherosclerosis. Atherosclerosis 2013;229:18-22.

6 Mendel I, Yacov N, Harats D, Breitbart E: Therapies Targeting Innate Immunity for Fighting Inflammation in Atherosclerosis. Curr Pharm Design 2015;21:1185-1195.

7 Winter J, Jung S, Keller S, Gregory RI, Diederichs S: Many roads to maturity: microRNA biogenesis pathways and their regulation. Nat Cell Biol 2009;11:228-234.

8 Contreras J, Rao DS: MicroRNAs in inflammation and immune responses. Leukemia 2012;26:404-413.

-9 Rayner KJ, Fernandez-Hernando C, Moore KJ: MicroRNAs regulating lipid metabolism in atherogenesis. Thromb Haemost 2012;107:642-647.

10 Quiat D, Olson EN: MicroRNAs in cardiovascular disease: from pathogenesis to prevention and treatment. J Clin Invest 2013;123:11-18.

11 Heymans S, Corsten MF, Verhesen W, Carai P, van Leeuwen RE, Custers K, Peters T, Hazebroek M, Stöger L, Wijnands E, Janssen BJ, Creemers EE, Pinto YM, Grimm D, Schürmann N, Vigorito E, Thum T, Stassen F, Yin X, Mayr M, de Windt LJ, Lutgens E, Wouters K, de Winther MP, Zacchigna S, Giacca M, van Bilsen M, Papageorgiou AP, Schroen B: Macrophage microRNA-155 promotes cardiac hypertrophy and failure. Circulation 2013;128:1420-1432.

-12 Tili E, Michaille JJ, Cimino A, Costinean S, Dumitru CD, Adair B, Fabbri M, Alder H, Liu CG, Calin GA, Croce CM: Modulation of miR-155 and miR-125b levels following lipopolysaccharide/TNF-alpha stimulation and their possible roles in regulating the response to endotoxin shock. J Immunol 2007;179:5082-5089.

13 Xiao B, Liu Z, Li BS, Tang B, Li W, Guo G, Shi Y, Wang F, Wu Y, Tong WD, Guo H, Mao XH, Zou QM: Induction of microRNA-155 during Helicobacter pylori infection and its negative regulatory role in the inflammatory response. J Infec Dis 2009;200:916-925.

-14 Nazari-Jahantigh M, Wei Y, Noels H, Akhtar S, Zhou Z, Koenen RR, Heyll K, Gremse F, Kiessling F, Grommes J, Weber C, Schober A: MicroRNA-155 promotes atherosclerosis by repressing Bcl6 in macrophages. J Clin Invest 2012;122:4190-4202.

15 Faraoni I, Antonetti FR, Cardone J, Bonmassar E: miR-155 gene: a typical multifunctional microRNA. BBAMol Basis Dis 2009;1792:497-505.

16 O'Neill LA, Sheedy FJ, McCoy CE: MicroRNAs: the fine-tuners of Toll-like receptor signalling. Nat Rev Immunol 2011;11:163-175.

17 Kurowska-Stolarska M, Alivernini S, Ballantine LE, Asquith DL, Millar NL, Gilchrist DS, Reilly J, Ierna M, Fraser AR, Stolarski B, McSharry C, Hueber AJ, Baxter D, Hunter J, Gay S, Liew FY, McInnes IB: MicroRNA-155 as a proinflammatory regulator in clinical and experimental arthritis. Proc Natl Acad Sci USA 2011;108:11193-11198.

18 Davey GM, Heath WR, Starr R: SOCS1: a potent and multifaceted regulator of cytokines and cell-mediated inflammation. Tissue antigens 2006;67:1-9.

19 Tsuchiya S, Kobayashi Y, Goto Y, Okumura H, Nakae S, Konno T, Tada K: Induction of maturation in cultured human monocytic leukemia cells by a phorbol diester. Cancer Res 1982;42:1530-1536.

20 da Costa Martins PA, Salic K, Gladka MM, Armand AS, Leptidis S, el Azzouzi H, Hansen A, Coenen-de Roo CJ, Bierhuizen MF, van der Nagel R, van Kuik J, de Weger R, de Bruin A, Condorelli G, Arbones ML, Eschenhagen T, De Windt LJ: MicroRNA-199b targets the nuclear kinase Dyrk1a in an auto-amplification loop promoting calcineurin/NFAT signalling. Nat Cell Biol 2010;12:1220-1227.

-21 Thum T, Gross C, Fiedler J, Fischer T, Kissler S, Bussen M, Galuppo P, Just S, Rottbauer W, Frantz S, Castoldi M, Soutschek J, Koteliansky V, Rosenwald A, Basson MA, Licht JD, Pena JT, Rouhanifard SH, Muckenthaler MU, Tuschl T, Martin GR, Bauersachs J, Engelhardt S: MicroRNA-21 contributes to myocardial disease by stimulating MAP kinase signalling in fibroblasts. Nature 2008;456:980-984.

-22 Paigen B, Morrow A, Holmes PA, Mitchell D, Williams RA: Quantitative assessment of atherosclerotic lesions in mice. Atherosclerosis 1987;68:231-240.

23 Ryo A, Suizu F, Yoshida Y, Perrem K, Liou YC, Wulf G, Rottapel R, Yamaoka S, Lu KP: Regulation of NFkappaB signaling by Pin1-dependent prolyl isomerization and ubiquitin-mediated proteolysis of p65/RelA. Mol Cell 2003;12:1413-1426.

24 Virtue A, Mai J, Yin Y, Meng S, Tran T, Jiang X, Wang H, Yang XF: Structural evidence of anti-atherogenic microRNAs. Front Biosci 2011;16:3133-3145. 


\section{Cellular Physiology Cell Physiol Biochem 2015;36:1371-1381 \begin{tabular}{l|l} 
and Biochemistry Published onlIne: July UI, 2015 & $\begin{array}{l}\text { C) 2015 S. Karger AG, Basel } \\
\text { www.karger.com/cpb }\end{array}$ \\
\hline
\end{tabular}}

Yang et al: SOCS1-miR-155 and Atherosclerosis Inflammation

25 Small EM, Olson EN: Pervasive roles of microRNAs in cardiovascular biology. Nature 2011;469:336-342.

26 Wang J, Song Y, Zhang Y, Xiao H, Sun Q, Hou N, Guo S, Wang Y, Fan K, Zhan D, Zha L, Cao Y, Li Z, Cheng X, Zhang Y, Yang X.: Cardiomyocyte overexpression of miR-27b induces cardiac hypertrophy and dysfunction in mice. Cell Res 2012;22:516-527.

27 Zernecke A, Bidzhekov K, Noels H, Shagdarsuren E, Gan L, Denecke B, Hristov M, Köppel T, Jahantigh MN, Lutgens E, Wang S, Olson EN, Schober A, Weber C: Delivery of microRNA-126 by apoptotic bodies induces CXCL12-dependent vascular protection. Sci Signal 2009;2:ra81.

28 Zhang Y, Liu D, Chen X, Li J, Li L, Bian Z, Sun F, Lu J, Yin Y, Cai X, Sun Q, Wang K, Ba Y, Wang Q, Wang D, Yang J, Liu P, Xu T, Yan Q, Zhang J, Zen K, Zhang CY.: Secreted monocytic miR-150 enhances targeted endothelial cell migration. Mol Cell 2010;39:133-144.

29 Tian FJ, An LN, Wang GK, Zhu JQ, Li Q Zhang YY, Zeng A, Zou J, Zhu RF, Han XS, Shen N, Yang HT, Zhao XX, Huang S, Qin YW, Jing Q: Elevated microRNA-155 promotes foam cell formation by targeting HBP1 in atherogenesis. Cardiovasc Res 2014;103:100-110.

- 30 Baker BJ, Akhtar LN, Benveniste EN.: SOCS1 and SOCS3 in the control of CNS immunity. Trends Immunol 2009;30:392-400.

- 31 He Y, Zhang W, Zhang R, Zhang H, Min W: SOCS1 inhibits tumor necrosis factor-induced activation of ASK1JNK inflammatory signaling by mediating ASK1 degradation. J Biol Chem 2006;281:5559-5566.

-32 Fang H, Lin J, Wang L, Xie P, Wang X, Fu J, Ai W, Chen S, Chen F, Zhang F, Su Y, Li D: Kruppel-like factor 2 regulates dendritic cell activation in patients with acute coronary syndrome. Cell Physiol Biochem 2013;32:931-941.

-33 Meng Z, Yan C, Deng Q, Dong X, Duan ZM, Gao DF, Niu XL: Oxidized low-density lipoprotein induces inflammatory responses in cultured human mast cells via Toll-like receptor 4. Cell Physiol Biochem 2013;31:842-853.

34 Lin J, Chang W, Dong J, Zhang F, Mohabeer N, Kushwaha KK, Wang L, Su Y, Fang H, Li D: Thymic stromal lymphopoietin over-expressed in human atherosclerosis: potential role in Th17 differentiation. Cell Physiol Biochem 2013;31:305-318.

-35 Wei Y, Nazari-Jahantigh M, Chan L, Zhu M, Heyll K, Corbalán-Campos J, Hartmann P, Thiemann A, Weber C, Schober A: The microRNA-342-5p fosters inflammatory macrophage activation through an Akt1- and microRNA-155-dependent pathway during atherosclerosis. Circulation 2013;127:1609-1619.

- 36 Sullivan RP, Fogel LA, Leong JW, Schneider SE, Wong R, Romee R, Thai TH, Sexl V, Matkovich SJ, Dorn GW 2nd, French AR, Fehniger TA: MicroRNA-155 tunes both the threshold and extent of NK cell activation via targeting of multiple signaling pathways. J Immunol 2013;191:5904-5913.

- 37 Fenner JE1, Starr R, Cornish AL, Zhang JG, Metcalf D, Schreiber RD, Sheehan K, Hilton DJ, Alexander WS, Hertzog PJ: Suppressor of cytokine signaling 1 regulates the immune response to infection by a unique inhibition of type I interferon activity. Nat Immunol 2006;7:33-39.

-38 Qing Y, Costa-Pereira AP, Watling D, Stark GR.: Role of tyrosine 441 of interferon-gamma receptor subunit 1 in SOCS-1-mediated attenuation of STAT1 activation. J Biol Chem 2005;280:1849-1853.

39 Fitzgerald KA, McWhirter SM, Faia KL, Rowe DC, Latz E, Golenbock DT, Coyle AJ, Liao SM, Maniatis T: IKKepsilon and TBK1 are essential components of the IRF3 signaling pathway. Nat Immunol 2003;4:491496.

-40 Ng SL, Friedman BA, Schmid S, Gertz J, Myers RM, Tenoever BR, Maniatis T: IkappaB kinase epsilon (IKK(epsilon)) regulates the balance between type I and type II interferon responses. Proc Natl Acad Sci USA 2011;108:21170-21175.

41 Hou J, Lin L, Zhou W, Wang Z, Ding G, Dong Q, Qin L, Wu X, Zheng Y, Yang Y, Tian W, Zhang Q, Wang C, Zhang Q, Zhuang SM, Zheng L, Liang A, Tao W, Cao X: Identification of miRNomes in human liver and hepatocellular carcinoma reveals miR-199a/b-3p as therapeutic target for hepatocellular carcinoma. Cancer cell 2011;19:232-243.

-42 Wang X, Guo B, Li Q, Peng J, Yang Z, Wang A, Li D, Hou Z, Lv K, Kan G, Cao H, Wu H, Song J, Pan X, Sun Q Ling S, Li Y, Zhu M, Zhang P, Peng S, Xie X, Tang T, Hong A, Bian Z, Bai Y, Lu A, Li Y, He F, Zhang G, Li Y: miR-214 targets ATF4 to inhibit bone formation. Nat Med 2013;19:93-100.

43 Krutzfeldt J, Rajewsky N, Braich R, Rajeev KG, Tuschl T, Manoharan M, Stoffel M: Silencing of microRNAs in vivo with 'antagomirs'. Nature 2005;438:685-689. 